\section{CVIA}

REVIEW ARTICLE

pISSN 2508-707X / eISSN 2508-7088 https://doi.org/10.22468/cvia.2016.00059 CVIA 2017;1(1):23-37

CrossMark $\leftarrow$ click for updates

Received: October 25, 2016

Revised: November 14, 2016

Accepted: November 14, 2016

Corresponding author

Yung Liang Wan, MD

Department of Medical Imaging

and Intervention, Chang Gung

Memorial Hospital at Linkou,

Institute for Radiological Research,

College of Medicine,

Chang Gung University, 5 Fusing Road,

Kueisan District, Taoyuan 33305, Taiwan

Tel: 886-3-3281200 ext. 2575

Fax: 886-3-3971936

E-mail: ylw0518@cgmh.org.tw

\section{Corresponding author}

Kuo-Chun Hung, MD

Department of Cardiology،

Chang Gung Memorial Hospital

at Linkou, College of Medicine,

Chang Gung University, 5 Fusing Road,

Kueisan District, Taoyuan 33305, Taiwan

Tel: 886-3-3281200 ext. 8119

Fax: 886-3-3289134

E-mail: 0062@cgmh.org.tw

*These authors contributed equally to this work.

\title{
Imaging of Cardiac and Pericardial Masses
}

\author{
Patricia Wanping Wu ${ }^{1 *}$, Shyh-Jye Chen ${ }^{2 *}$, Wan-Ching Lin, \\ Chun-Bi Chang ${ }^{1}$, Wen-Yu Chuang ${ }^{3}$, Ming-Yi Hsu', Yuan-Chang Liu ${ }^{1}$, \\ Jaw-Ji Chu', Pyng-Jing Lin ${ }^{4}$, Ming-Shien Wen ${ }^{5}$, Kuo-Chun Hung ${ }^{5}$, \\ Yung-Liang Wan ${ }^{1}$ \\ 'Department of Medical Imaging and Intervention, Chang Gung Memorial Hospital at Linkou, \\ Institute for Radiological Research, College of Medicine, Chang Gung University, Taoyuan, Taiwan \\ 2Department of Medical Imaging, National Taiwan University Hospital, College of Medicine, \\ National Taiwan University, Taipei, Taiwan \\ ${ }^{3}$ Departments of Pathology, ${ }^{4}$ Cardiovascular Surgery, ${ }^{5}$ Cardiology, Chang Gung Memorial Hospital \\ at Linkou, College of Medicine, Chang Gung University, Taoyuan, Taiwan
}

Cardiac tumors are uncommon, with primary cardiac tumors being exceedingly rare. Benign primary cardiac tumors are more common than malignant primary cardiac tumors. Common benign cardiac tumors include myxoma, lipoma, papillary fibroelastoma, rhabdomyoma, fibroma, hemangioma, and paraganglioma. Malignant cardiac tumors include metastasis, angiosarcoma, rhabdomyosarcoma, and lymphoma. Clinical presentation depends on tumor pathology, location, and hemodynamic effects. Echocardiography, computed tomography, and magnetic resonance imaging often play a key role in differentiating between benign and malignant tumors, assessing the extent of tumor involvement, presurgical planning and management, and postoperative follow-up of cardiac masses.

Key words Cardiac tumor - Computed tomography - Magnetic resonance imaging.

\section{INTRODUCTION}

Cardiac masses are uncommon, and primary cardiac tumors are especially rare, with a prevalence of 0.001 to $0.28 \%$ of the general population in autopsy studies [1]. They can be either benign or malignant [2]. The clinical presentation of cardiac masses depends on their pathology, location, and hemodynamic effects [3].

Imaging studies often play a key role in the diagnosis and management of cardiac masses. Echocardiography, chest radiography, computed tomography (CT), and magnetic resonance (MR) imaging, with or without electrocardiogram (ECG)-gating, are frequently used modalities for evaluating cardiac masses [3-

(a) This is an Open Access article distributed under the terms of the Creative Commons Attribution Non-Commercial License (http://creativecommons.org/licenses/bync/3.0) which permits unrestricted non-commercial use, distribution, and reproduction in any medium, provided the original work is properly cited.
19]. Cardiac masses can be classified by location as intraluminal (including valvular and non-valvular), mural, and pericardial. Many cardiac tumors tend to grow in certain locations, which can be helpful in determining differential diagnoses. Table 1 shows the typical locations of common cardiac masses.

Cardiac masses can also be classified as benign tumors, malignant tumors or non-tumoral masses. Benign primary cardiac tumors are more common than malignant primary cardiac tumors, with about $25 \%$ of primary cardiac tumors being malignant [13]. Some imaging features that may help distinguish benign from malignant neoplasms include location, size, margins, the presence of a feeding artery, calcification, or pericardial effusion $[3,9]$. This article describes the imaging features of common benign and malignant cardiac masses.

The patient characteristics and imaging features of common cardiac tumors are listed in Table 2. 
Imaging of Cardiac and Pericardial Masses

Table 1. Typical locations of various cardiac masses $[2,13,14]$

\begin{tabular}{|c|c|c|}
\hline Intraluminal & Mural & Pericardial \\
\hline Non-valvular & - Metastasis & - Metastasis \\
\hline - Metastasis & - Lipomatous hypertrophy & - Pericardial cyst \\
\hline - Thrombus & - Lipoma & - Lymphoma \\
\hline - Myxoma & - Sarcoma & - Fat necrosis \\
\hline - Sarcoma & - Lymphoma & - Sarcoma \\
\hline - Hemangioma & - Rhabdomyoma & - Paraganglioma \\
\hline Valvular & - Fibroma & \\
\hline - Metastasis & - Hemangioma & \\
\hline - Endocarditis & & \\
\hline • Myxoma & & \\
\hline - Fibroelastoma & & \\
\hline - Caseous necrosis & & \\
\hline
\end{tabular}

\section{BENIGN CARDIAC TUMORS}

\section{Myxoma}

Myxomas are the most common primary cardiac tumor, accounting for $25-50 \%$ of cases [20]. They occur most often in patients 30 to 60 years old, with a higher prevalence in women $[21,22]$. Most occur sporadically, although there have been cases of familial lesions and lesions associated with a clinical complex [23]. The classic clinical triad consists of 1) symptoms related to blood flow obstruction, 2) embolic events, and 3) constitutional symptoms such as fever, malaise, and weight loss [24]. A combination of two or more signs of this triad is suggestive of myxoma [25]. In a series of 83 patients with cardiac myxomas, 71 (88\%) were symptomatic [21]. About $59-75 \%$ of myxomas occur in the left atrium, often with a pedunculated attachment to the atrial septum near the fossa ovalis. The rest occur in the right atrium, right ventricle, left ventricle, or involve both atria or even multiple chambers [21,24]. Thromboembolic events occur in about $30-40 \%$ of patients with myxomas, especially with myxomas that are large and friable [26].

On imaging, chest radiography may show direct signs of intracardiac calcifications (16\%) and cardiomegaly (35\%), or indirect signs of elevated left atrial pressure, prominent pulmonary trunk, pulmonary edema, and pleural effusion [21]. Echocardiography shows a well-defined, hyperechoic mass. CT demonstrates spherical or ovoid tumors with lobular or smooth contours, with an overall attenuation slightly lower or equal to that of myocardium. Coarse or punctate calcifications may be seen in about $14 \%$ of cases, and heterogeneous enhancement is seen after intravenous contrast administration. The tumor can be soft and mobile, and is usually located in the left atrium (Fig. 1) or right atrium (Fig. 2). Associated findings include tumor extension into the great vessels, tumor emboli in the aorta, and thromboembolic events such as stroke and splenic and renal infarcts [21]. On MR imaging, the tumor is typically heterogeneous in signal intensity, appearing hypo- or isointense to myocardium on T1-weighted images, hyperintense on T2-weighted images, and with heterogeneous enhancement after intravenous gadolinium administration [7,21].

Cardiac myxomas are treated surgically and have an excellent long-term prognosis [27]. MR imaging can aid in surgical planning by providing accurate assessment of the size, location, and point of attachment of the myxoma to the cardiac wall or valve [21]. Recurrence may occur rarely (Fig. 3), especially in men, younger patients, and patients with multicentric and familial type myxomas, smaller myxomas, and myxomas located in the ventricles [28-30]. For these patients, postoperative follow-up with imaging surveillance for the first 10 years is recommended [30]. In non-hereditary myxomas, the recurrence rate is low, and the necessity of long-term echocardiographic follow-up is questioned [31].

\section{Lipoma}

Lipomas are the second most common benign cardiac tumor. They are composed of mature adipose tissue and occur in a wide age range $[1,16,20]$. Lipomas have been reported in association with tuberous sclerosis complex [32]. Small lipomas are often asymptomatic and discovered incidentally, whereas larger or pericardial lipomas may manifest with symptoms such as compression of coronary arteries, arrhythmias, and outflow obstruction $[9,33]$.

The fat density of a lipoma is readily identified on CT $[16,20]$. On MR images, the tumor demonstrates high signal on both T1- and T2-weighted images, and decreased signal on fat saturation sequences $[14,20]$. Lipomas must be differentiated from a number of fat-containing lesions in and around the heart, including lipomatous hypertrophy of the interatrial septum, fatty myocardial foci in tuberous sclerosis complex, arrhythmogenic right ventricular dysplasia, ischemic cardiomyopathy, and liposarcoma [34]. An encapsulated appearance with a lack of ag- 

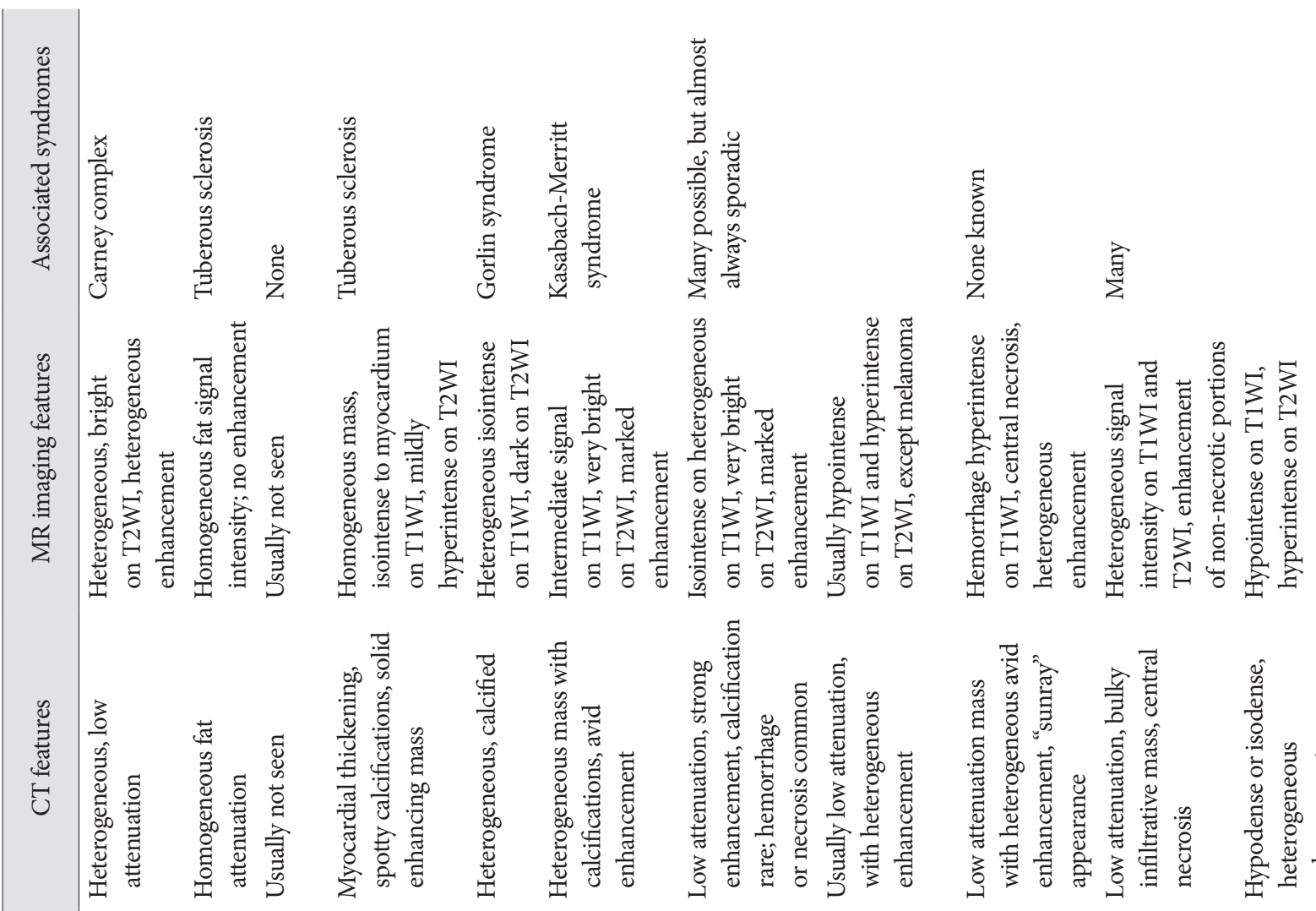

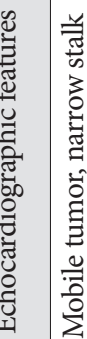
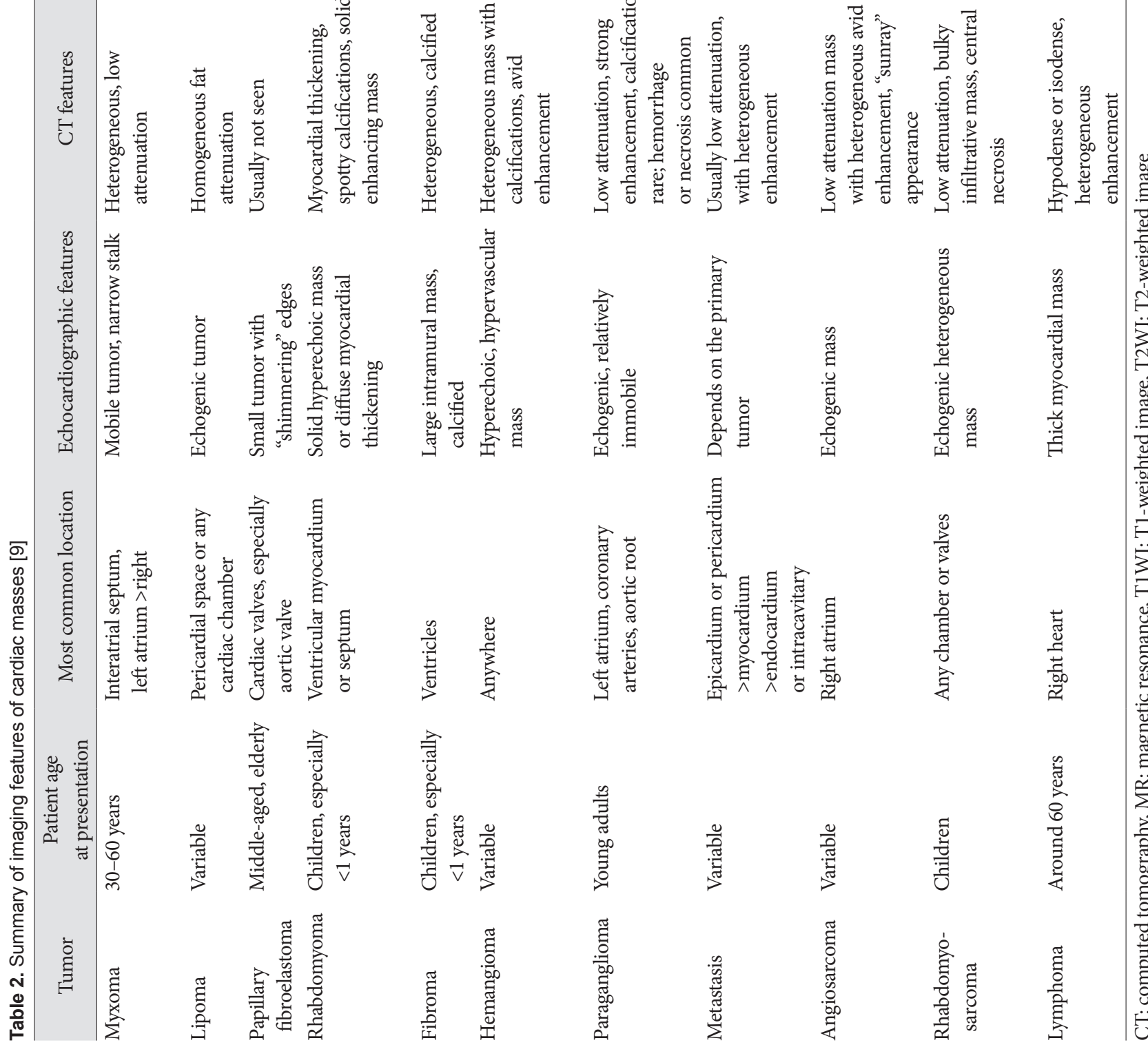

咅咅
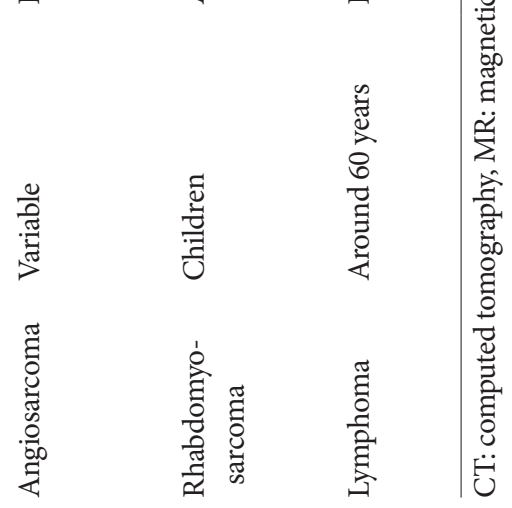

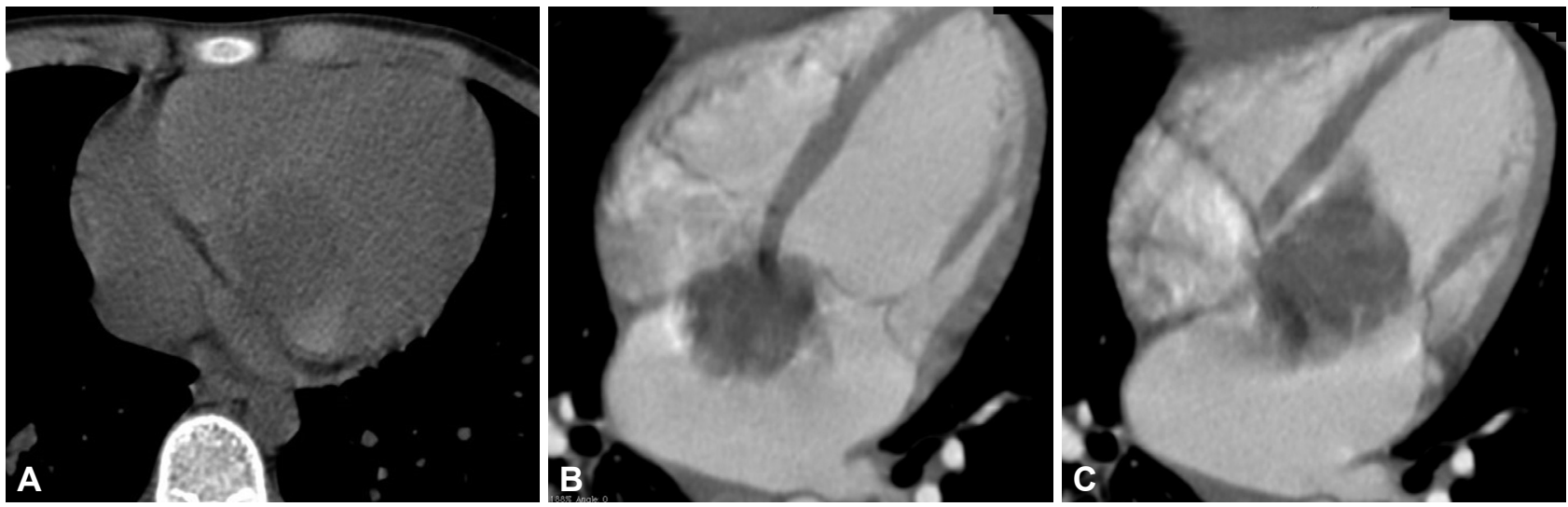

Fig. 1. A 9-year-old girl with episodes of sudden onset exertional dyspnea. Transthoracic echocardiography (not shown) reveal a left atrial mass. Cardiac computed tomograms before $(A)$ and after $(B$ and $C$ ) intravenous contrast administration demonstrate a round, low-density mass attached to the left atrial side of the interatrial septum, a location typical for myxomas. A slight change in shape and movement through the mitral valve were observed during the cardiac cycle. Surgical pathology revealed a typical benign myxoma.
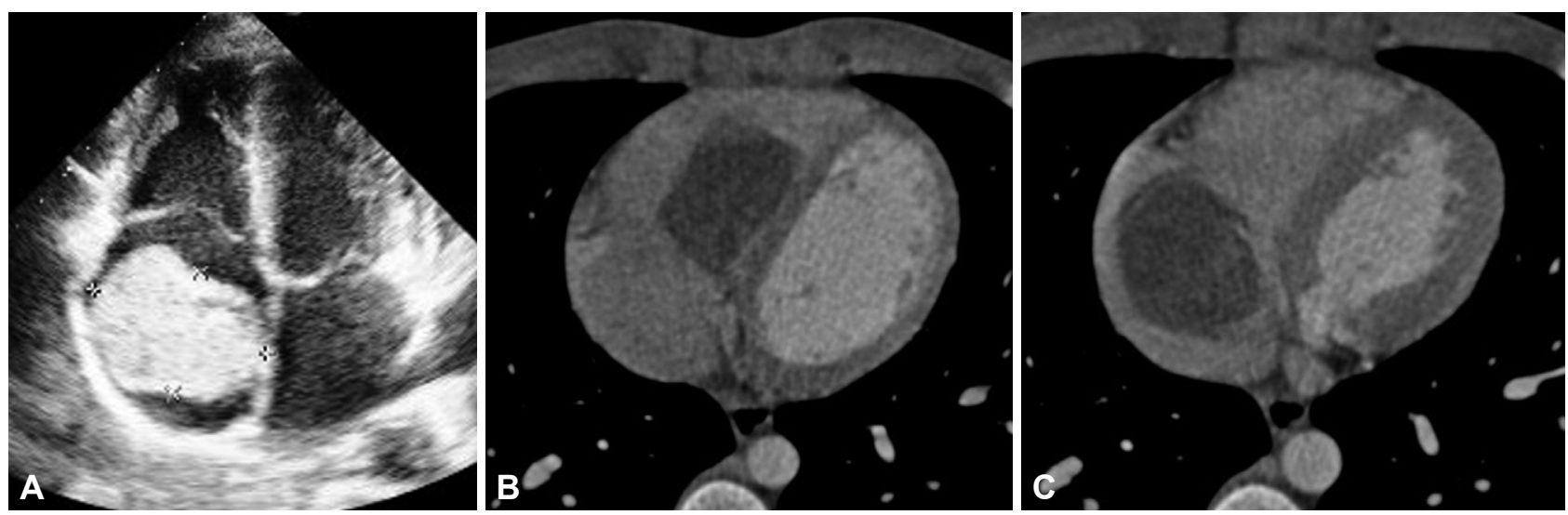

Fig. 2. A 16-year-old boy with palpitations. Transthoracic echocardiography (A) shows a large hyperechoic mass in the right atrium. Contrast-enhanced computed tomograms in systole (B) and diastole (C) demonstrate a large, homogenous, low-density tumor arising from the right atrial side of the lower interatrial septum. The mass is seen in the right atrium during systole and prolapses into the proximal right ventricle during diastole. The pathology showed a typical myxoma.

gressive features, such as local invasion and metastases, favor a diagnosis of benign lipoma [34]. While symptomatic lipomas are treated surgically, the management of asymptomatic lipomas is controversial. Some authors advocate for conservative followup, whereas others prefer surgical resection due to the possibility of liposarcoma and events related to arrhythmia and obstruction [35].

\section{Papillary fibroelastoma}

Papillary fibroelastoma is the most common neoplasm of the cardiac valves and papillary muscles [36]. The tumor is composed of delicate, papillary frond-like projections and is likened to a sea anemone $[9,37]$. Papillary fibroelastomas occur in a wide age range, with the highest prevalence in patients 70-79 years old, and are equally common in men and women [38]. The aortic valve is the most common site, followed by the mitral valve [38]. The majority of papillary fibroelastomas are small and asymptomatic, but some may present with symptoms such as transient ischemic attack and stroke in patients with mitral valve tumors, or sudden cardiac death and myocardial infarction in patients with aortic valve tumors [38]. Valvular insufficiency is not a feature of papillary fibroelastoma, owing to its location away from the free edge of the leaflet [39].

Fibroelastomas are typically diagnosed by echocardiography, where they are seen as small mobile masses attached to the valve (Fig. 4). Because of its papillary projections, a fibroelastoma may demonstrate a stippled edge with a "shimmer" or "vibration" at the interface of the tumor with the surrounding blood, a sign that can help distinguish the tumor from a thrombus [9,39]. ECGgated CT angiography may reveal a nodular lesion attached to the valve, away from the valvular free edge [13]. On MR images, fibroelastomas are of intermediate signal on both T1- and T2weighted images, and are well-demonstrated on cine MR images [40].

Surgical excision is the treatment standard with valve-sparing techniques, leaflet repair, or valve replacement. Recurrence has not been reported in the literature [37]. 


\section{Rhabdomyoma}

Rhabdomyomas are the most common primary cardiac tumor in children, particularly in infants, with up to $50 \%$ associated with tuberous sclerosis [41,42]. Most are asymptomatic and discovered incidentally by prenatal ultrasound or the presence of a heart murmur during neonatal screening [2]. Some patients may present with signs of heart failure or cardiac arrhythmias [41]. Rhabdomyomas may regress spontaneously in size and
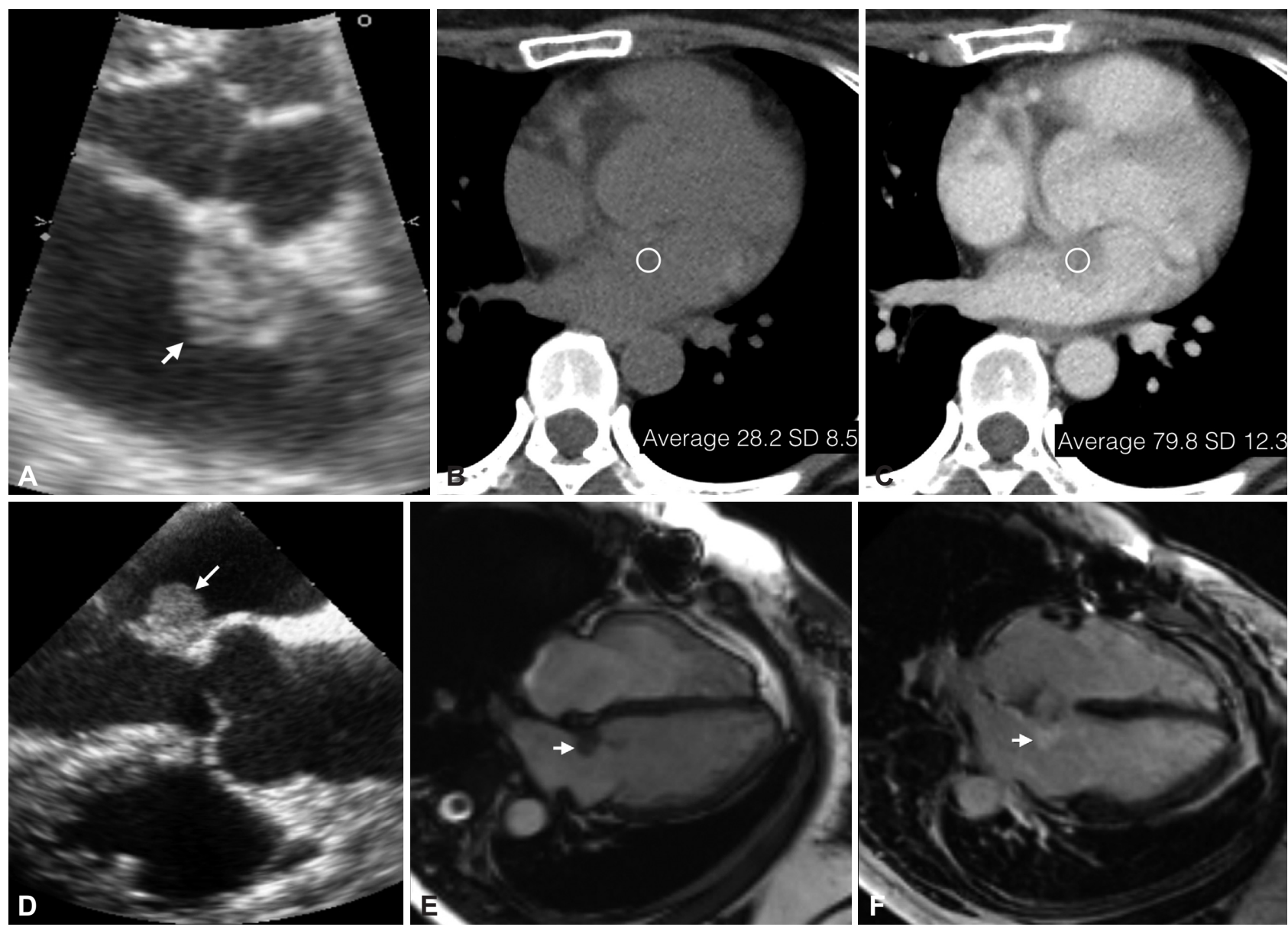

Fig. 3. A 39-year-old woman with progressive exertional dyspnea for months. Echocardiography (A) shows a hyperechoic mass (arrow) on the left atrial medial wall. Computed tomograms before $(B)$ and after $(C)$ contrast administration demonstrate an isodense enhancing mass in the left atrium. Surgical pathology revealed a myxoma. Two years later, follow-up echocardiogram (D) found a new hyperechoic mass (arrow) in the left atrium. Magnetic resonance imaging using pre-contrast T2-weighted (E) and post-contrast T1-weighted delayed phase (F) images in four-chamber view show a nodule (arrows) that is hyperintense to the myocardium on T2-weighted image and has delayed enhancement. Surgical pathology confirmed a recurrent myxoma.
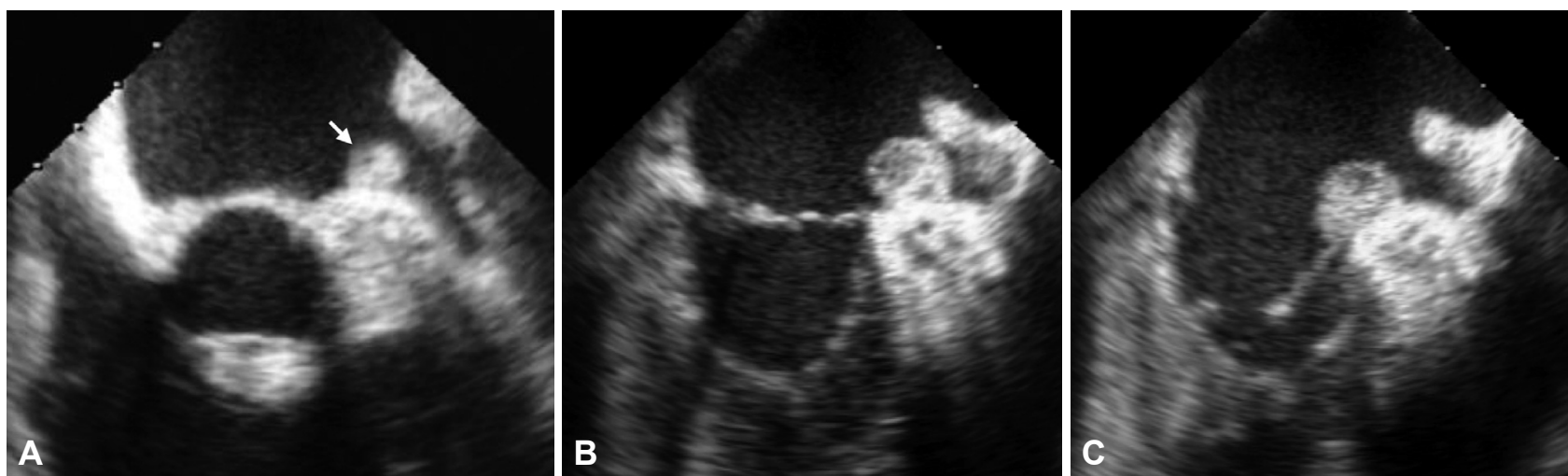

Fig. 4. A 47-year-old man had a transient ischemic attack. Echocardiography (A) shows a hyperechoic nodular lesion (arrow) in the left atrium, near the mitral annulus. Two years later, a follow-up echocardiogram in systolic (B) and diastolic (C) phases show progressive enlargement of the tumor, which moves with the mitral leaflet. Surgical pathology revealed a papillary fibroelastoma. 

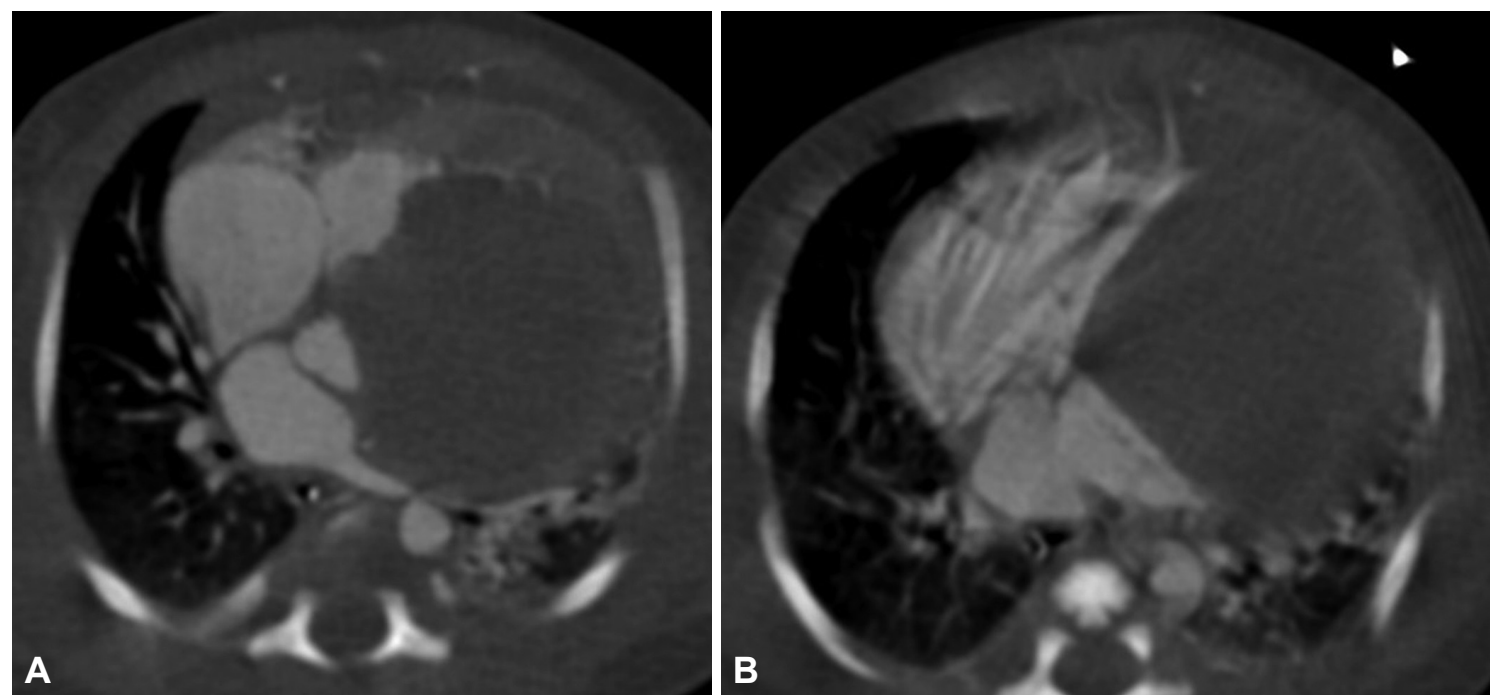

Fig. 5. A 1-day-old newborn with heart failure. Contrast-enhanced cardiac computed tomograms during arterial phase reveal a huge soft tissue density mass that impinges on both the inlet $(A)$ and outlet $(B)$ of the left ventricle. The mass is homogenous and slightly hypodense to the adjacent myocardium. The final pathology showed a rhabdomyoma.
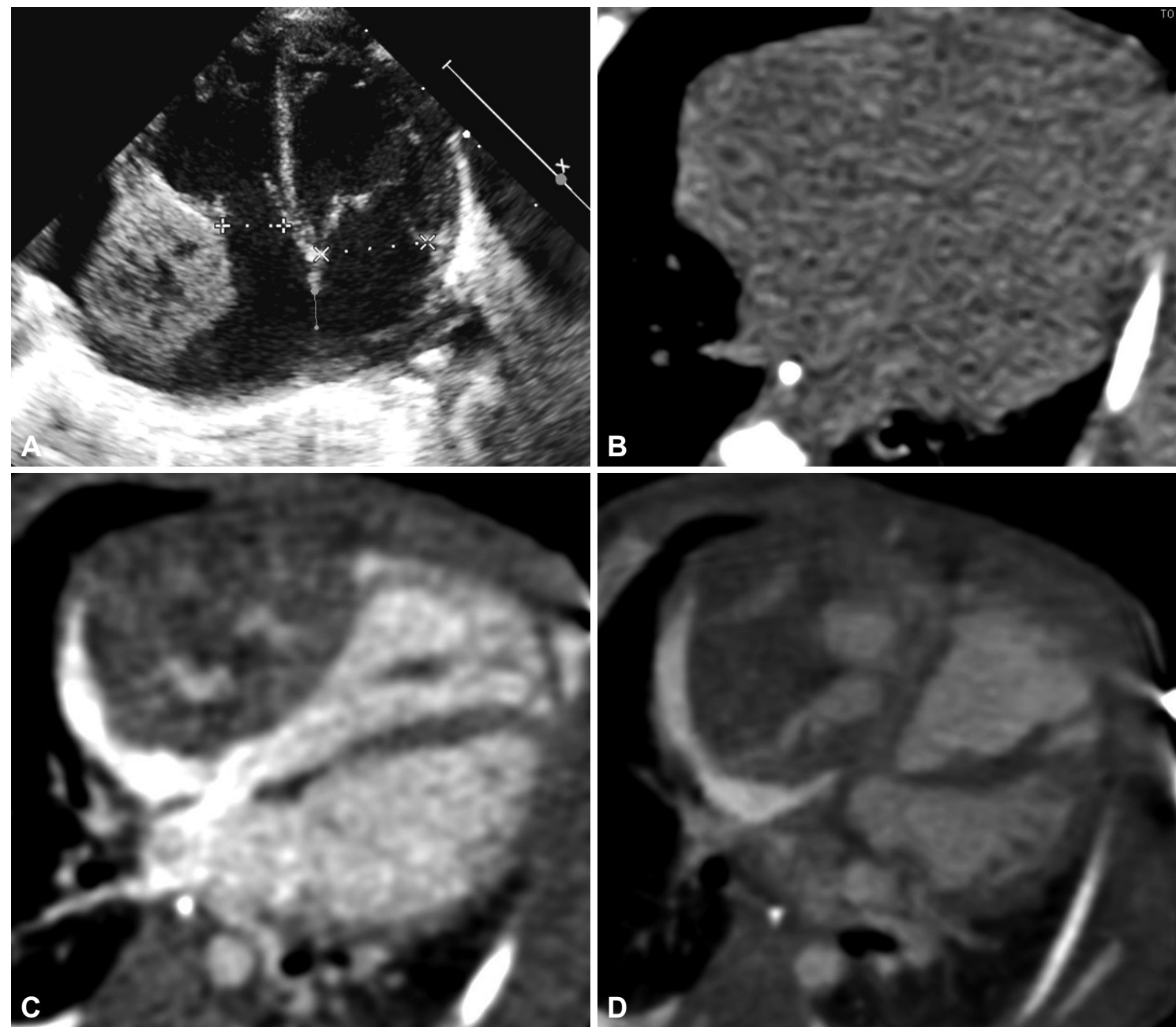

Fig. 6. A 7-day-old male newborn with hepatomegaly. Transthoracic echocardiography (A) shows a large hyperechoic mass arising from the anterior wall of the right atrium with hypoechoic tubular structures in the center. Cardiac computed tomograms before (B) and after contrast during arterial phase $(C$ and $D)$ delineate a huge muscle-density tumor with prominent enhancing channels and lakes that impinge on the tricuspid opening, suggestive of a hypervascular tumor. The final pathology showed a capillary hemangioma. 
number, especially in patients younger than 4 years old [43].

On echocardiography, rhabdomyomas appear as solid hyperechoic masses, usually located in the ventricular myocardium or ventricular septum. In some cases, the lesions are small and multiple, and appear as diffuse myocardial thickening [2]. CT may demonstrate myocardial thickening with spotty calcifications or a solid homogeneous mass (Fig. 5) [14]. MR images typically show a homogeneous mass within or attached to the ventricular myocardium, isointense on T1-weighted images, mildly hyperintense on $\mathrm{T} 2$-weighted images, and with enhancement after intravenous gadolinium administration [44].

Surgery is not routinely recommended unless the patient is symptomatic, usually with left ventricular outflow obstruction or arrhythmias; these cases respond well to surgical excision [2].

\section{Fibroma}

Fibromas are the second most common primary cardiac tumor in infants and children. About one-third of fibromas occur before the age of 1 year [2]. Fibromas may occur in association with polyposis syndrome such as familial adenomatous polyposis and Gorlin (nevoid basal cell carcinoma) syndrome [45]. Some patients are asymptomatic, while others may present with heart failure, arrhythmias, and sudden death, likely due to involvement of the cardiac conduction system [2].

On imaging, chest radiography may demonstrate a focal car- diac bulge or contour abnormality if the tumor involves the ventricular free wall. Tumor calcifications may be seen in about $25 \%$ of cases [2]. Fibromas on echocardiography appear as heterogeneous echogenic masses that are sometimes multifocal and may occasionally have central calcifications, with hypokinesia of the affected myocardium [46]. CT demonstrates a heterogeneous mural mass with enhancement after intravenous contrast administration; calcifications are visible in about $25 \%$ of cases [2]. On MR images, fibromas are typically seen as intramyocardial lesions involving the ventricular septum or free wall, with well-defined borders, heterogeneous signal on T1- and T2-weighted images, and strong enhancement after intravenous gadolinium administration, with or without a hypoenhancing core correlating with fibrous tissue [44].

The treatment of choice is surgical excision, with generally favorable outcomes [46]. Patients with very extensive tumors may benefit from partial tumor excision [47]. Recurrence is rare after surgical treatment [46].

\section{Hemangioma}

Cardiac hemangiomas are rare, accounting for about $5-10 \%$ of benign cardiac tumors, and can affect patients of all age groups [2]. Most patients are asymptomatic, but some may present with exertional dyspnea, heart failure, pericarditis, and thromboembolic disease [48].
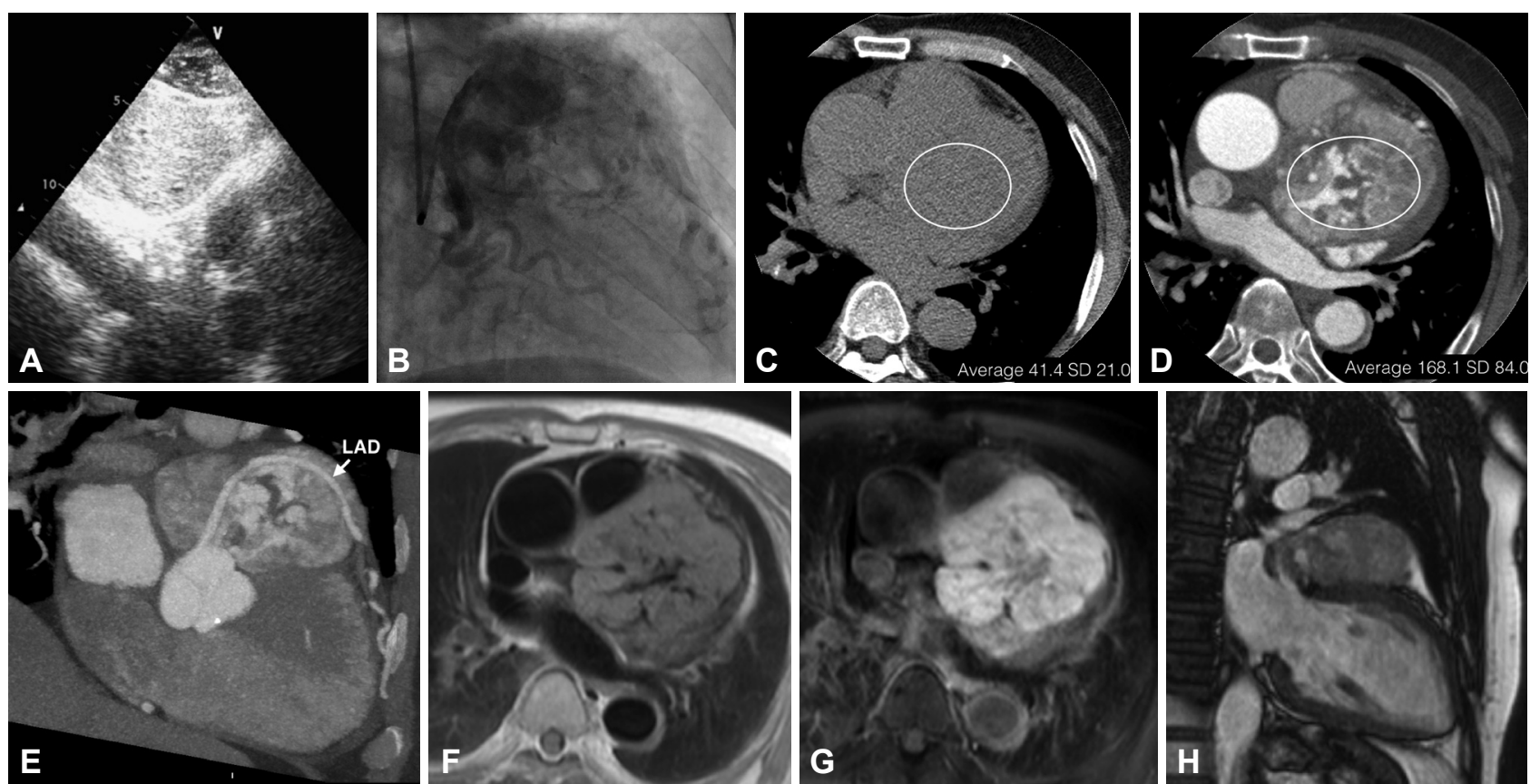

Fig. 7. A 67-year-old man with frequent angina pectoris, dyspnea, diaphoresis, and palpitations for about one year. Echocardiogram (A) shows a large hyperechoic heterogeneous mass, just above the left atrial appendage and within the pericardial space. Coronary left main angiogram (B) reveals a hypervascular mass. Computed tomography without contrast (C) and computed tomographic angiography with contrast enhancement in axial (D) and oblique (E) views reveal a heterogeneous, avidly enhancing mass encasing the left main and left anterior descending arteries. Magnetic resonance imaging in axial T1-weighted images (F), axial T1-fat-suppressed images with gadolinium enhancement $(\mathrm{G})$, and two-chamber view T2-weighted images $(\mathrm{H})$ demonstrate a T1-isointense, T2-hyperintense, and strongly enhancing mass. Surgical pathology showed a paraganglioma. LAD: left anterior descending artery. 
On imaging, hemangiomas may be found anywhere in the cardiac region, from the pericardium to the subendocardial structures [48]. CT images may demonstrate a heterogeneous mass with foci of calcifications and avid enhancement after intravenous contrast administration (Fig. 6) [13]. On MR images, hemangiomas exhibit intermediate signal on T1-weighted images, bright signal on T2-weighted images, and marked enhancement after intravenous gadolinium administration [49].

\section{Paraganglioma}

Cardiac paragangliomas are very rare, with less than 160 cases reported in the literature [50]. They arise from the neuroendocrine cells in the normal cardiac ganglia and may come from visceral paraganglia in the left atrium, most frequently in the posterior wall or the left atrial roof, or from the interatrial septum or paraganglia along the coronary arteries [9]. Patients are usually younger adults, with a mean age of 39.7 years at diagnosis [50,51]. In cases of functioning paragangliomas, patients may present with symptoms of catecholamine overproduction such as hypertension, headaches, palpitations, and diaphoresis [51]. At echocardiography, paragangliomas typically appear as large, echogenic masses, and encasement of the coronary arteries may be seen [9]. On CT images, they appear as circumscribed, heterogeneous, low-attenuation masses that enhance avidly after contrast administration [9]. At MR imaging, paragangliomas exhibit isointensity on T1-weighted images, bright hyperintensity on T2-weighted images, and intense enhancement with contrast administration (Fig. 7) [9,13]. Central necrosis and hemorrhage may be present, as well as internal calcifications [50]. Surgical resection is the treatment of choice and can be curative with good long-term survival, but may be difficult in cases of coronary artery involvement [52].

\section{MALIGNANT CARDIAC TUMORS}

\section{Metastases}

Cardiac metastases are 20 to 40 times more frequent than primary tumors $[6,20]$. The most common primary sites are the
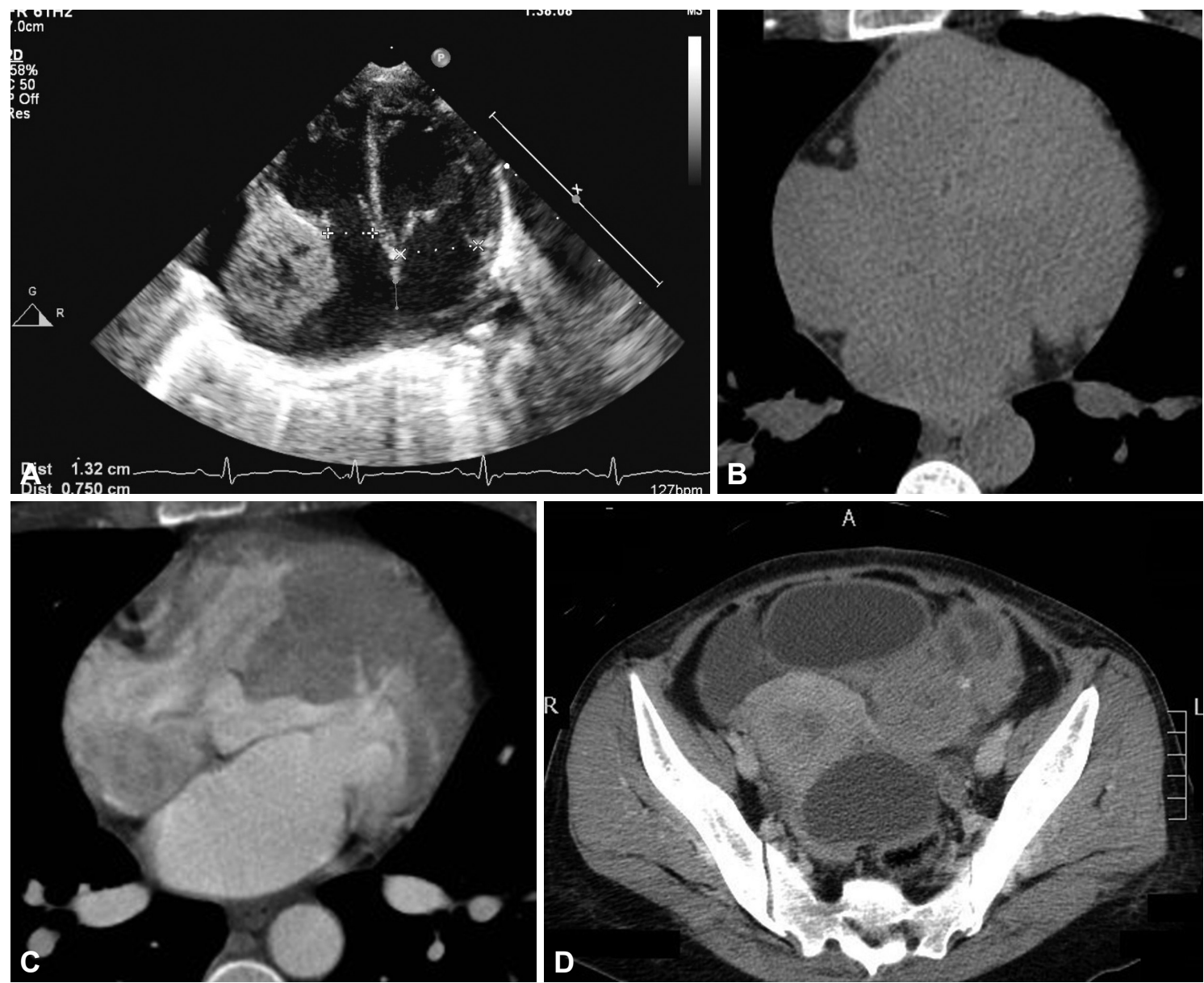

Fig. 8. This 33-year-old female was found to have a new heart murmur. Transthoracic echocardiography (A) suggests a subaortic stenosis by hypertrophy of the interventricular septum. Cardiac computed tomograms before (B) and after (C) contrast demonstrate a large, irregular, soft tissue density mass with less enhancement than the adjacent myocardium at the upper portion of the interventricular septum. This tumor impinges on both the left and right ventricular outflow tracts. Further workup by pelvic computed tomography (D) identified a malignant tumor of her left ovary. The pathology showed a metastatic tumor at the interventricular septum from ovarian cancer. 

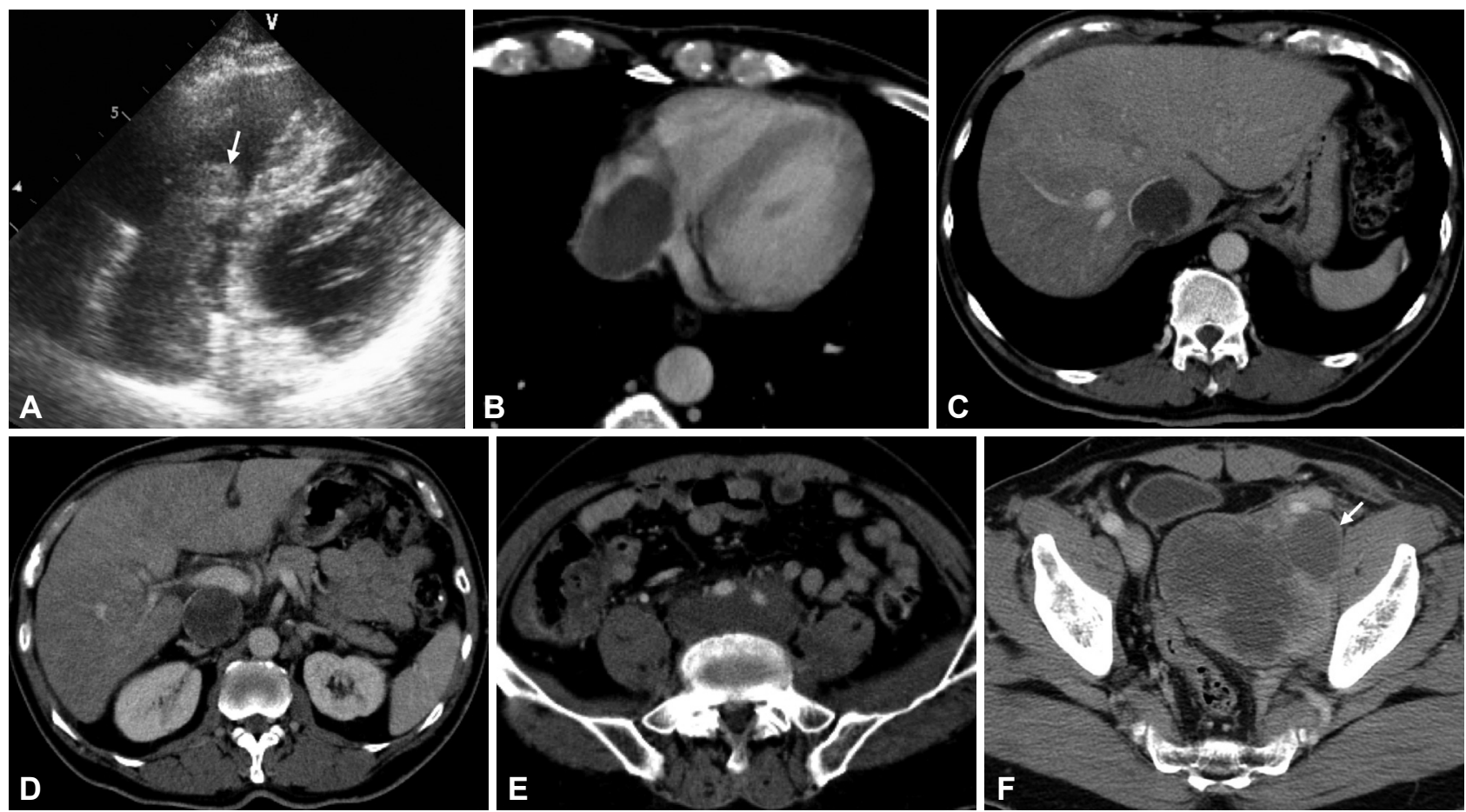

Fig. 9. A 54-year-old man had previously undergone surgery and radiotherapy for malignant fibrous histiocytoma in the left pelvis. Echocardiography (A) shows an echogenic irregular mass (arrow) within the right atrium. Contrast-enhanced computed tomography (B-E) demonstrates a massive thrombus in the inferior vena cava extending all the way from the iliac veins to the right atrium. Pelvic computed tomography two years ago (F) shows a left pelvic tumor with thrombosis of the left external iliac vein (arrow). Surgical pathology revealed a metastatic sarcoma.
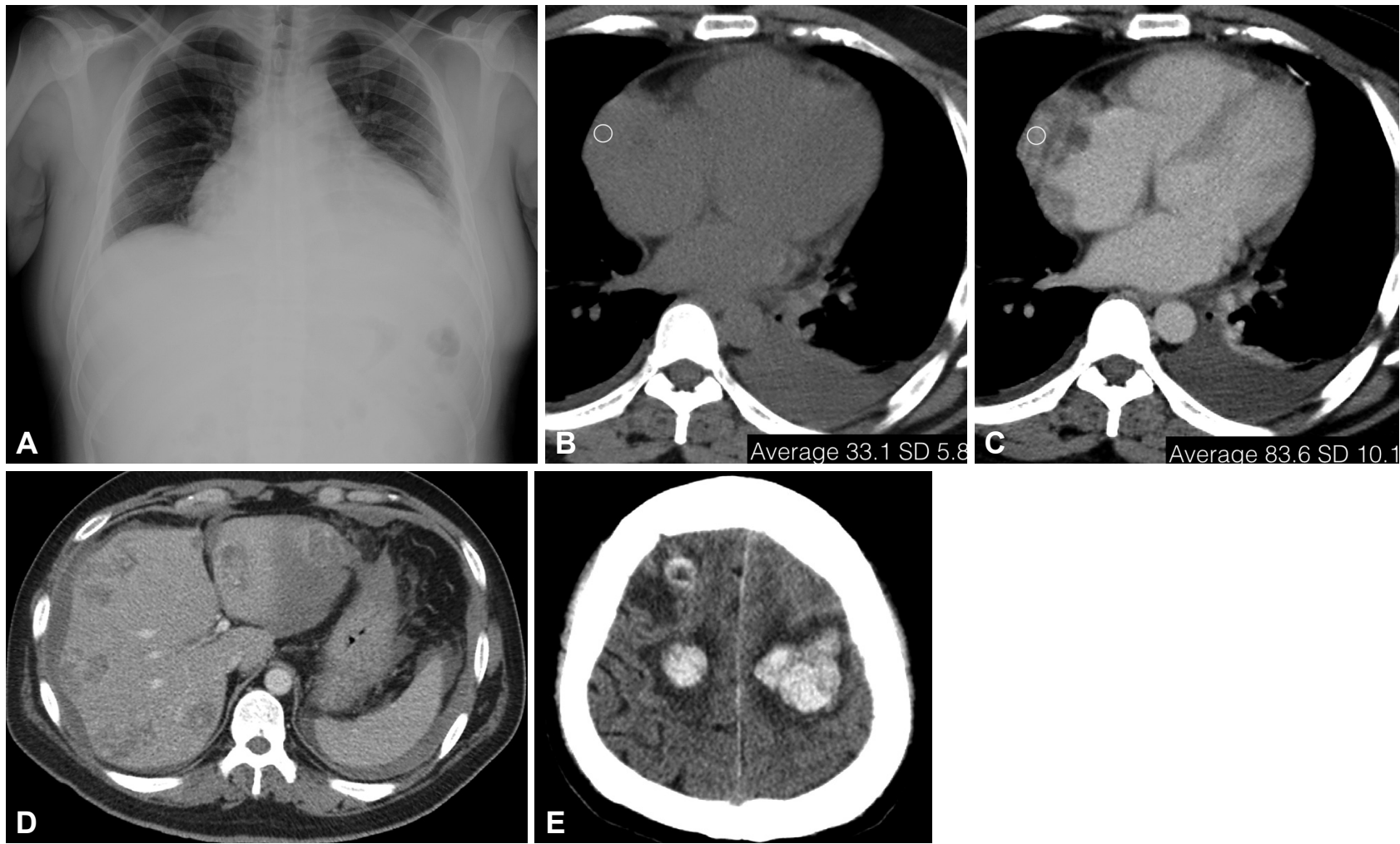

Fig. 10. A 33-year-old man with progressively severe dyspnea for one week. Chest radiography (A) shows cardiomegaly. Echocardiography (not shown) revealed a massive pericardial effusion, which appeared bloody during pericardiocentesis. Computed tomograms of the chest before $(B)$ and after $(C)$ contrast administration demonstrate an irregular, heterogeneously enhancing mass at the right atrial wall. Surgical pathology revealed angiosarcoma. One year later, the patient passed away due to bleeding of the metastatic tumors in the liver (D) and brain (E). 
lung, breast, and hematologic malignancies, in that order. Malignant melanoma is also prone to metastasize to the myocardium, but only presents in the late stages [18].

The pericardium and epicardium are involved in $65-70 \%$ of patients, usually by direct invasion. The myocardium is involved in approximately $30 \%$ of patients (Fig. 8). Endovascular extension with endocardial or intracavitary tumor is rare, and usually occurs by extension from the inferior vena cava into the right atrium (Fig. 9) [18].

Imaging presentation varies with the primary origin of the tumor, and appearances and enhancing patterns identical to the primary lesion are clues for diagnosis. The presence of metastases involving other organs is also an indirect sign. In general, cardiac metastases are low-attenuation masses with heterogeneous enhancement on CT images, hypointense on T1-weighted images, and hyperintense on T2-weighted MR images. The exception is malignant melanoma, which demonstrates hyperintensity on T1-weighted images $[6,7,18]$. Malignant pericardial effusion frequently occurs; exudative or hemorrhagic effusions exhibit high signal on T1-weighted images, which can be differentiated from other pericardial effusions $[6,7]$.

\section{Angiosarcoma}

Angiosarcoma is the most common primary cardiac malignancy of adulthood, accounting for approximately $9 \%$ of primary cardiac tumors [6]. It is more common in men and occurs over a wide age range [53]. Unlike other sarcomas, about $80 \%$ of angiosarcomas involve the right atrial free wall and may extend to the pericardium $[6,13,54]$. Right atrial perforation and cardiac tamponade due to angiosarcoma have been reported [55].
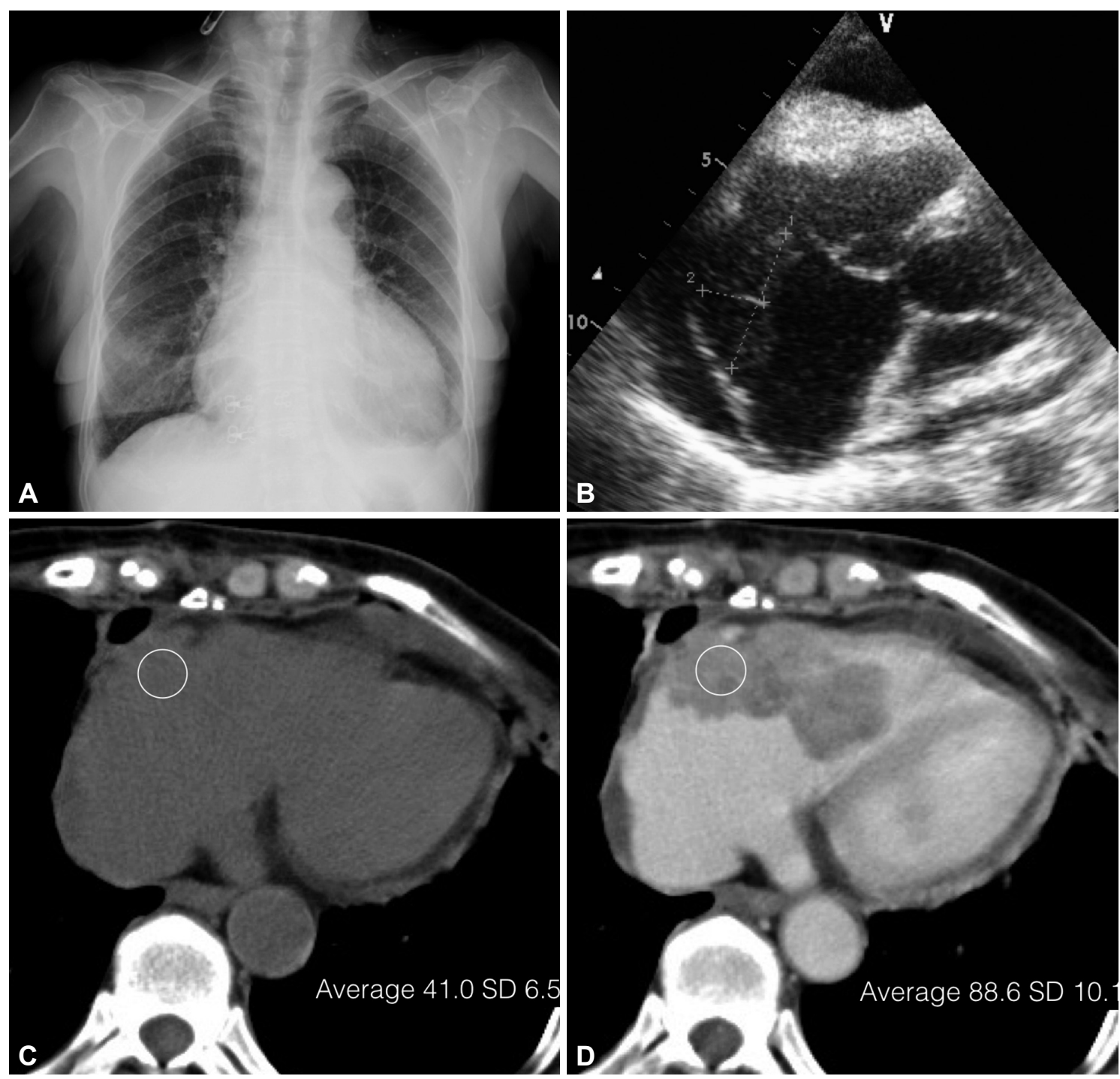

Fig. 11. A 76-year-old woman with bilateral leg edema and abdominal fullness for about two weeks. Chest radiography (A) shows cardiomegaly and left pleural effusion. Echocardiography (B) reveals irregular thickening of the right atrial and right ventricular walls. Computed tomography without $(C)$ and with $(D)$ contrast enhancement demonstrates an isodense, lobulated, enhancing mass in the right atrium and right ventricle. Biopsy and systemic survey confirmed the diagnosis of a primary diffuse large B-cell lymphoma of the heart. 

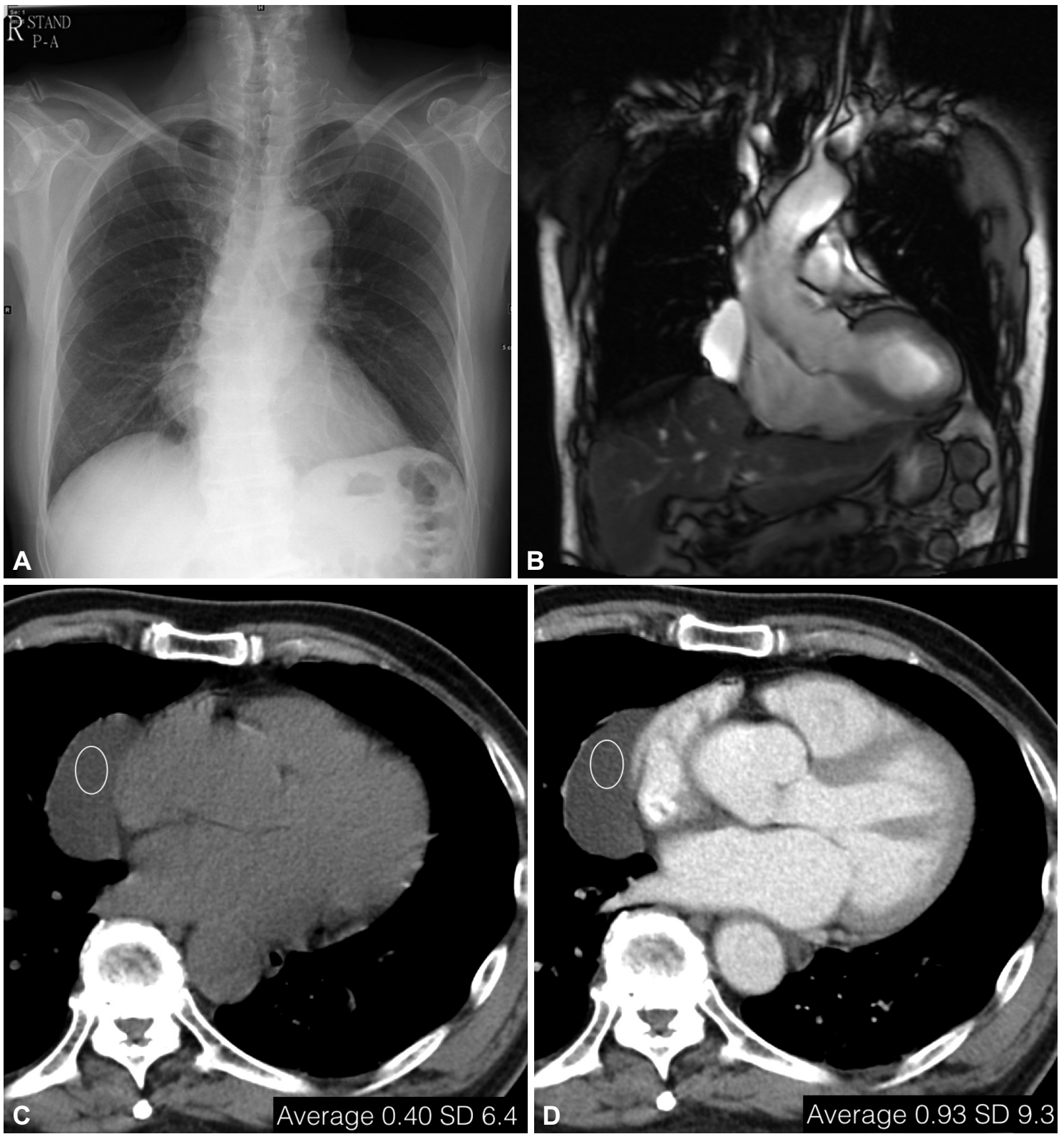

Fig. 12. A 73-year-old male with atrial flutter was admitted for ablation. Chest radiography (A) shows a focal bulging at the right heart border. Coronal T2-weighted magnetic resonance image (B) shows a well-defined hyperintense lesion abutting the right atrial wall. Computed tomograms without (C) and with (D) contrast enhancement show a non-enhancing water-density lesion, compatible with a pericardial cyst.

On CT images, they usually present as low-attenuation lesions that enhance heterogeneously after intravenous contrast administration [13]. There are two main morphologic appearances: focal nodules with cauliflower appearance protruding into a cardiac chamber, and diffusely infiltrative masses extending along the epicardial surface (Fig. 10) [6]. MR images may demonstrate hemorrhage as hyperintense foci on T1-weighted images. Areas of central necrosis and hemorrhage are characteristic findings and result in heterogeneous signal intensity on T2-weighted images $[6,7,18,56]$. Intravenous contrast administration usually demonstrates avid enhancement [13]. In cases of pericardial infiltration, a "sunray appearance" may be seen as a result of linear enhancement along vascular spaces [56]. Tumor invasion to the pericardium usually appears as a sheet-like thickening of the pericardium and the presence of pericardial effusion [53]. The right coronary artery may be involved, posing a risk for vessel rupture [18]. Angiosarcomas metastasize in $66-89 \%$ of patients, most often to the lungs, liver, and brain (Fig. 9D and E). Presentation is late and metastasis is often seen at the time of diagnosis [6,7].

\section{Rhabdomyosarcoma}

Rhabdomyosarcomas are the most common primary cardiac malignancy in children, but also occur rarely in adults [7]. The 

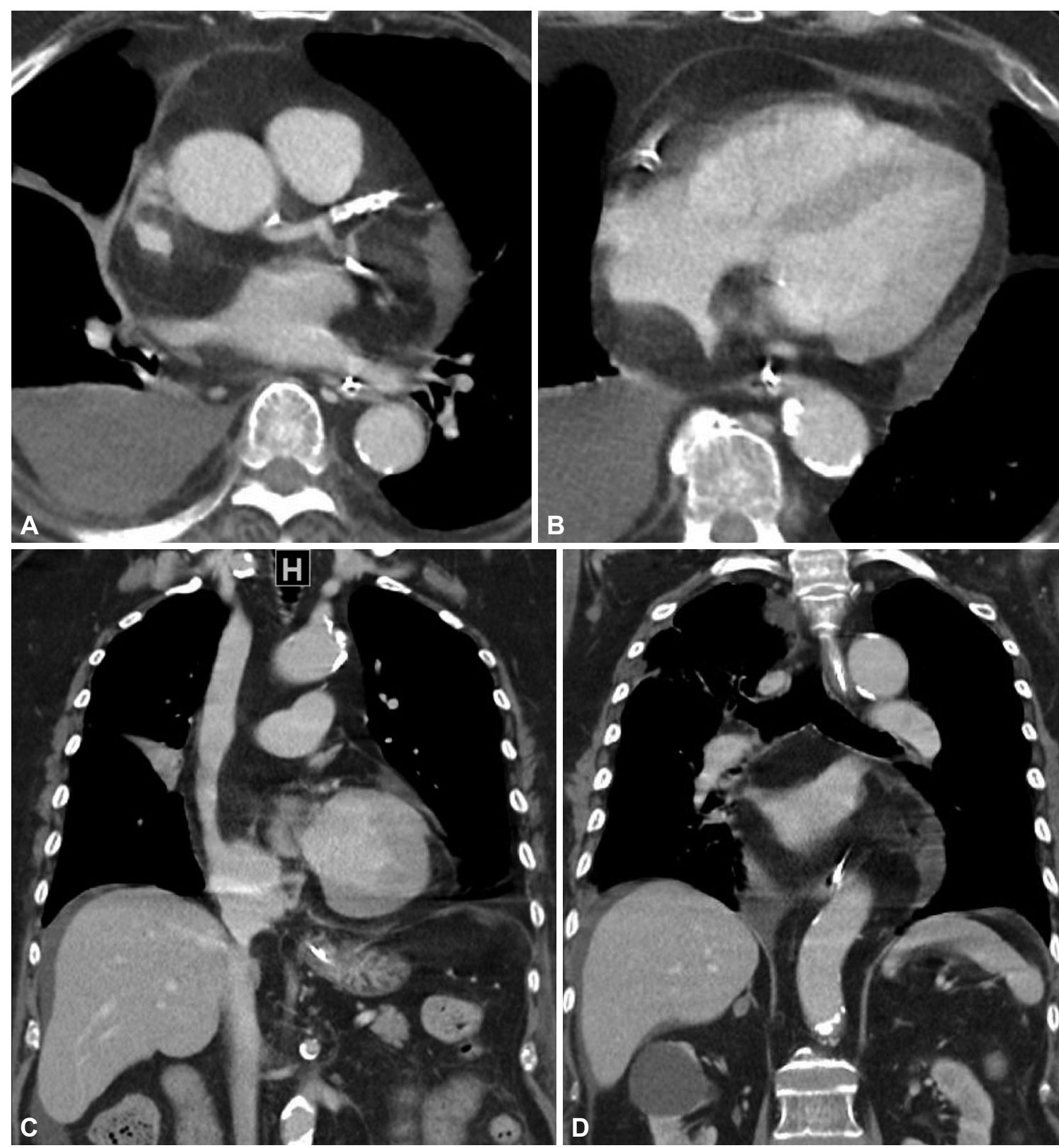

Fig. 13. A 77-year-old man with wheezing. Chest radiography (not shown) showed mediastinal widening. Contrast-enhanced computed tomograms in axial ( $A$ and $B$ ) and coronal ( $C$ and $D$ ) images demonstrate mass-like lipomatosis of the interatrial septum, as well as abundant fat in the pericardial, mediastinal, subcutaneous, and retroperitoneal spaces, suggestive of diffuse lipomatosis. There is mass effect on the left atrium, superior vena cava, and coronary sinus, as well as widening of the carinal angle (D). Right pleural effusion is seen, possibly due to compression of the right inferior pulmonary vein.

embryonal subtype occurs in children, whereas the much less pleomorphic subtype occurs in adults [1]. These tumors may occur in any chamber, but tend to involve the valves more often than other primary cardiac sarcomas. Clinical symptoms depend on the location of the tumor, but congestive heart failure is a common presentation [7].

On CT images, rhabdomyosarcomas typically appear as lowattenuation, bulky, infiltrative masses with central necrosis [9]. On MR images, the tumors exhibit heterogeneous signal intensity on both T1- and T2-weighted images. Contrast enhance- ment of the solid, non-necrotic portions is usually seen [7].

\section{Other sarcomas}

A number of other sarcomas may occur in the heart, including pleomorphic sarcoma, fibrosarcoma, osteosarcoma, leiomyosarcoma, and liposarcoma [13]. These are rare entities with variable imaging findings, but most arise from the left atrial wall and exhibit slow infiltrative growth patterns [57]. Surgery is rarely feasible and considered as palliative therapy for most patients [57]. 
Table 3. Quiz $[12,13,18]$

\begin{tabular}{|c|c|}
\hline Questions & Answers \\
\hline 1. What is the most common cardiac sarcoma? & 1. Angiosarcoma \\
\hline 2. What is special about the locations of angiosarcomas? & 2. Right atrial involvement more frequent than left atrial involve- \\
\hline 3. What is the most common primary cardiac tumor? & ment, unlike other sarcomas \\
\hline 4. In cases of cardiac tumor associating with renal or brain infarcts, & 3. Myxoma \\
\hline what is the most probable diagnosis? & 4. Myxoma \\
\hline 5. What is the most common tumor of cardiac valves? & 5. Papillary fibroelastoma \\
\hline 6. What cardiac mass is most likely to be associated with tuberous & 6. Rhabdomyoma and lipoma \\
\hline sclerosis? & 7. Lipomatous hypertrophy of the interatrial septum \\
\hline 7. What condition has a dumbbell-shape sparing the fossa ovalis? & 8. Rhabdomyoma and fibroma \\
\hline 8. What are the two most common congenital pediatric tumors? & \\
\hline
\end{tabular}

\section{Lymphoma}

Primary cardiac lymphomas are extremely rare, with secondary lymphoma being much more common [7]. In primary cardiac lymphomas, the most common is the diffuse large B-cell type [48], which usually occurs in patients around 60 years of age and in men more often than women. Lymphoma tends to involve the right side of the heart and infrequently involves the valves [1].

On CT images, lymphomas appear as thick myocardial or pericardial masses that are hypodense or isodense relative to the myocardium, with heterogeneous enhancement after intravenous contrast administration (Fig. 11) [58]. On MR images, lymphomas typically exhibit low signal intensity on T1-weighted images and high signal on T2-weighted images [59].

\section{Non-tumoral masses}

Several mass-like lesions in the heart can mimic tumors. The crista terminalis is a normal anatomical structure that may sometimes be mistaken for a tumor [18]. Thrombi are also common, and can usually be distinguished from tumors such as myxomas by shape and location [11]. Thrombi are usually smaller than myxomas, do not enhance, and are typically located in the left atrial appendage or posterior wall; myxomas tend to be attached at the fossa ovalis. In addition, thrombi do not prolapse through the cardiac valves as myxomas might [60]. Pericardial cysts can be identified by their well-demarcated appearance with water density on CT, low signal on T1-weighted images, high signal on T2-weighted images, and lack of contrast enhancement (Fig. 12) [6]. Lipomatous hypertrophy of the interatrial septum is seen on CT as a "dumbbell-shaped" hypodense mass involving the interatrial septum, sparing the fossa ovalis (Fig. 13) [18]. Caseous necrosis of the mitral valve occurs as a rare variant of mitral annular calcification and typically involves the posterior mitral annulus at the atrioventricular groove. In the early phases, the mass is hyperintense on both T1- and T2-weighted images [6]. Valvular vegetations occur in the setting of infective endocarditis and can be identified as low-attenuation masses involv- ing the valvular leaflet free edge, for which cardiac CT is both highly sensitive (97\%) and specific (88\%) [18].

\section{CONCLUSION}

Masses occurring in and around the heart are rare and diverse. Although the majority of primary cardiac tumors are benign, radiologists and clinicians must be familiar with the typical imaging features of cardiac masses in order to correctly diagnose and manage these lesions (Table 3). A combination of imaging modalities may aid in the diagnostic process.

\section{Conflicts of Interest}

The authors declare that they have no conflict of interest.

\section{Acknowledgments}

This study was supported partly by a research grant from the Ministry of Sciences and Technology, Taiwan, with grant number 103-2314-B-182-012-MY3.

\section{REFERENCES}

1. Burke A, Virmani R. Tumors of the heart and great vessels. Fascicle 16, 3rd Series. In: Burke A, Virmani R, eds. Atlas of tumor pathology. Washington, DC: Armed Forces Institute of Pathology, 1996;1-98.

2. Grebenc ML, Rosado de Christenson ML, Burke AP, Green CE, Galvin JR. Primary cardiac and pericardial neoplasms: radiologic-pathologic correlation. Radiographics 2000;20:1073-1103; quiz 1110-1, 1112.

3. Rajiah P, Kanne JP, Kalahasti V, Schoenhagen P. Computed tomography of cardiac and pericardiac masses. J Cardiovasc Comput Tomogr 2011;5:1629.

4. Syed IS, Feng D, Harris SR, Martinez MW, Misselt AJ, Breen JF, et al. MR imaging of cardiac masses. Magn Reson Imaging Clin N Am 2008;16:137164, vii.

5. Randhawa K, Ganeshan A, Hoey ET. Magnetic resonance imaging of cardiac tumors: part 1, sequences, protocols, and benign tumors. Curr Probl Diagn Radiol 2011;40:158-168.

6. Motwani M, Kidambi A, Herzog BA, Uddin A, Greenwood JP, Plein S MR imaging of cardiac tumors and masses: a review of methods and clinical applications. Radiology 2013;268:26-43.

7. Sparrow PJ, Kurian JB, Jones TR, Sivananthan MU. MR imaging of cardiac tumors. Radiographics 2005;25:1255-1276.

8. Mundinger A, Gruber HP, Dinkel E, Geibel A, Beck A, Wimmer B, et al. Imaging in cardiac mass lesions. Radiat Med 1992;10:135-140.

9. Araoz PA, Mulvagh SL, Tazelaar HD, Julsrud PR, Breen JF. CT and MR 
imaging of benign primary cardiac neoplasms with echocardiographic correlation. Radiographics 2000;20:1303-1319.

10. Meng Q, Lai H, Lima J, Tong W, Qian Y, Lai S. Echocardiographic and pathologic characteristics of primary cardiac tumors: a study of 149 cases. Int J Cardiol 2002;84:69-75.

11. Tatli S, Lipton MJ. CT for intracardiac thrombi and tumors. Int J Cardiovasc Imaging 2005;21:115-131.

12. Attili AK, Chew FS. Imaging of cardiac masses and myocardial disease: self-assessment module. AJR Am J Roentgenol 2007;188(6 Suppl):S21-S25.

13. Hoey ET, Mankad K, Puppala S, Gopalan D, Sivananthan MU. MRI and CT appearances of cardiac tumours in adults. Clin Radiol 2009;64:12141230.

14. Kim EY, Choe YH, Sung K, Park SW, Kim JH, Ko YH. Multidetector CT and MR imaging of cardiac tumors. Korean J Radiol 2009;10:164-175.

15. O’Donnell DH, Abbara S, Chaithiraphan V, Yared K, Killeen RP, Cury RC, et al. Cardiac tumors: optimal cardiac MR sequences and spectrum of imaging appearances. AJR Am J Roentgenol 2009;193:377-387.

16. Anavekar NS, Bonnichsen CR, Foley TA, Morris MF, Martinez MW, Williamson EE, et al. Computed tomography of cardiac pseudotumors and neoplasms. Radiol Clin North Am 2010;48:799-816.

17. Chu LC, Johnson PT, Halushka MK, Fishman EK. Multidetector CT of the heart: spectrum of benign and malignant cardiac masses. Emerg Radiol 2012;19:415-428.

18. Kassop D, Donovan MS, Cheezum MK, Nguyen BT, Gambill NB, Blankstein R, et al. Cardiac masses on cardiac CT: a review. Curr Cardiovasc Imaging Rep 2014;7:9281.

19. Tumma R, Dong W, Wang J, Litt H, Han Y. Evaluation of cardiac masses by CMR-strengths and pitfalls: a tertiary center experience. Int J Cardiovasc Imaging 2016;32:913-920.

20. Shelton DK, Caputo G. Cardiac imaging in acquired diseases. In: Brant WE, Helms CA, eds. Fundamentals of diagnostic radiology. 4ed. Philadelphia, PA: Lippincott Willams \& Wilkins, 2012;612-613.

21. Grebenc ML, Rosado-de-Christenson ML, Green CE, Burke AP, Galvin JR. Cardiac myxoma: imaging features in 83 patients. Radiographics 2002;22:673-689.

22. Butany J, Nair V, Naseemuddin A, Nair GM, Catton C, Yau T. Cardiac tumours: diagnosis and management. Lancet Oncol 2005;6:219-228.

23. Shetty Roy AN, Radin M, Sarabi D, Shaoulian E. Familial recurrent atrial myxoma: Carney's complex. Clin Cardiol 2011;34:83-86.

24. Markel ML, Waller BF, Armstrong WF. Cardiac myxoma. A review. Medicine (Baltimore) 1987;66:114-125.

25. Goodwin JF. Diagnosis of left atrial myxoma. Lancet 1963;1:464-468.

26. Reynen K. Cardiac myxomas. N Engl J Med 1995;333:1610-1617.

27. Keeling IM, Oberwalder P, Anelli-Monti M, Schuchlenz H, Demel U, Tilz GP, et al. Cardiac myxomas: 24 years of experience in 49 patients. Eur J Cardiothorac Surg 2002;22:971-977.

28. Gray IR, Williams WG. Recurring cardiac myxoma. Br Heart J 1985; 53:645-649.

29. McCarthy PM, Piehler JM, Schaff HV, Pluth JR, Orszulak TA, Vidaillet $\mathrm{HJ}$ Jr, et al. The significance of multiple, recurrent, and "complex" cardiac myxomas. J Thorac Cardiovasc Surg 1986;91:389-396.

30. Shah IK, Dearani JA, Daly RC, Suri RM, Park SJ, Joyce LD, et al. Cardiac myxomas: a 50-year experience with resection and analysis of risk factors for recurrence. Ann Thorac Surg 2015;100:495-500.

31. Vroomen M, Houthuizen P, Khamooshian A, Soliman Hamad MA, van Straten AH. Long-term follow-up of 82 patients after surgical excision of atrial myxomas. Interact Cardiovasc Thorac Surg 2015;21:183-188.

32. Winterkorn EB, Dodd JD, Inglessis I, Holmvang G, Thiele EA. Tuberous sclerosis complex and myocardial fat-containing lesions: a report of four cases. Clin Genet 2007;71:371-373.

33. Barbuto L, Ponsiglione A, Del Vecchio W, Altiero M, Rossi G, De Rosa D, et al. Humongous right atrial lipoma: a correlative CT and MR case report. Quant Imaging Med Surg 2015;5:774-777.

34. Pruente R, Restrepo CS, Ocazionez D, Suby-Long T, Vargas D. Fatty lesions in and around the heart: a pictorial review. Br J Radiol 2015;88:
20150157.

35. Wang H, Hu J, Sun X, Wang P, Du Z. An asymptomatic right atrial intramyocardial lipoma: a management dilemma. World J Surg Oncol 2015; 13:20.

36. Edwards FH, Hale D, Cohen A, Thompson L, Pezzella AT, Virmani R. Primary cardiac valve tumors. Ann Thorac Surg 1991;52:1127-1131.

37. Grinda JM, Couetil JP, Chauvaud S, D’Attellis N, Berrebi A, Fabiani JN, et al. Cardiac valve papillary fibroelastoma: surgical excision for revealed or potential embolization. J Thorac Cardiovasc Surg 1999;117:106-110.

38. Gowda RM, Khan IA, Nair CK, Mehta NJ, Vasavada BC, Sacchi TJ. Cardiac papillary fibroelastoma: a comprehensive analysis of 725 cases. Am Heart J 2003;146:404-410.

39. Klarich KW, Enriquez-Sarano M, Gura GM, Edwards WD, Tajik AJ, Seward JB. Papillary fibroelastoma: echocardiographic characteristics for diagnosis and pathologic correlation. J Am Coll Cardiol 1997;30:784-790.

40. Lembcke A, Meyer R, Kivelitz D, Thiele H, Barho C, Albes JM, et al. Images in cardiovascular medicine. Papillary fibroelastoma of the aortic valve: appearance in 64-slice spiral computed tomography, magnetic resonance imaging, and echocardiography. Circulation 2007;115:e3-e6.

41. Webb DW, Thomas RD, Osborne JP. Cardiac rhabdomyomas and their association with tuberous sclerosis. Arch Dis Child 1993;68:367-370.

42. Beghetti M, Gow RM, Haney I, Mawson J, Williams WG, Freedom RM. Pediatric primary benign cardiac tumors: a 15-year review. Am Heart J 1997;134:1107-1114.

43. Nir A, Tajik AJ, Freeman WK, Seward JB, Offord KP, Edwards WD, et al. Tuberous sclerosis and cardiac rhabdomyoma. Am J Cardiol 1995;76:419421.

44. Beroukhim RS, Prakash A, Buechel ER, Cava JR, Dorfman AL, Festa P, et al. Characterization of cardiac tumors in children by cardiovascular magnetic resonance imaging: a multicenter experience. J Am Coll Cardiol 2011;58:1044-1054.

45. Vidaillet HJ Jr. Cardiac tumors associated with hereditary syndromes. Am J Cardiol 1988;61:1355.

46. Burke AP, Rosado-de-Christenson M, Templeton PA, Virmani R. Cardiac fibroma: clinicopathologic correlates and surgical treatment. J Thorac Cardiovasc Surg 1994;108:862-870.

47. Beghetti M, Haney I, Williams WG, Mawson J, Freedom RM, Gow RM. Massive right ventricular fibroma treated with partial resection and a cavopulmonary shunt. Ann Thorac Surg 1996;62:882-884.

48. O’Sullivan PJ, Gladish GW. Cardiac tumors. Semin Roentgenol 2008;43: 223-233.

49. Oshima H, Hara M, Kono T, Shibamoto Y, Mishima A, Akita S. Cardiac hemangioma of the left atrial appendage: $\mathrm{CT}$ and MR findings. J Thorac Imaging 2003;18:204-206.

50. Semionov A, Sayegh K. Multimodality imaging of a cardiac paraganglioma. Radiol Case Rep 2016;11:277-281.

51. Wang JG, Han J, Jiang T, Li YJ. Cardiac paragangliomas. J Card Surg 2015;30:55-60

52. Brown ML, Zayas GE, Abel MD, Young WF Jr, Schaff HV. Mediastinal paragangliomas: the mayo clinic experience. Ann Thorac Surg 2008;86: 946-951.

53. Burazor I, Aviel-Ronen S, Imazio M, Markel G, Grossman Y, Yosepovich A, et al. Primary malignancies of the heart and pericardium. Clin Cardiol 2014;37:582-588.

54. Burke A. Primary malignant cardiac tumors. Semin Diagn Pathol 2008; 25:39-46.

55. Sakaguchi M, Minato N, Katayama Y, Nakashima A. Cardiac angiosarcoma with right atrial perforation and cardiac tamponade. Ann Thorac Cardiovasc Surg 2006;12:145-148.

56. Yahata S, Endo T, Honma H, Ino T, Hayakawa H, Ogawa M, et al. Sunray appearance on enhanced magnetic resonance image of cardiac angiosarcoma with pericardial obliteration. Am Heart J 1994;127:468-471.

57. Neragi-Miandoab S, Kim J, Vlahakes GJ. Malignant tumours of the heart: a review of tumour type, diagnosis and therapy. Clin Oncol (R Coll Radiol) 2007;19:748-756. 
58. Dorsay TA, Ho VB, Rovira MJ, Armstrong MA, Brissette MD. Primary cardiac lymphoma: CT and MR findings. J Comput Assist Tomogr 1993; 17:978-981.

59. Tada H, Asazuma K, Ohya E, Hayashi T, Nakai T, Nakayama T, et al. Images in cardiovascular medicine. Primary cardiac B-cell lymphoma. Cir- culation 1998;97:220-221.

60. Scheffel H, Baumueller S, Stolzmann P, Leschka S, Plass A, Alkadhi H, et al. Atrial myxomas and thrombi: comparison of imaging features on CT. AJR Am J Roentgenol 2009;192:639-645. 